\title{
I solation, identification, characterization and antibiogram of Pasteurella multocida isolated from pigs in Mizoram with special reference to progressive atrophic rhinitis
}

\author{
Zomuankima Varte, T. K. Dutta, P. Roychoudhury, Jubeda Begum and Rajesh Chandra
}

Department of Veterinary Microbiology, College of Veterinary Science and Animal Husbandry, Central Agricultural University, Selesih, Aizwal, Mizoram - 796014, India

Corresponding author: T. K. Dutta, email: tapandutta@rediffmail.com

Received: 16-12-2013, Revised: 23-01-2014, Accepted: 28-01-2014, Published online: 28-02-2014

doi: 10.14202/vetworld.2014.95-99 How to cite this article: Varte Z, Dutta TK, Roychoudhury P, Begum J and Chandra R (2014) Isolation, identification, characterization and antibiogram of Pasteurella multocida isolated from pigs in Mizoram with special reference to progressive atrophic rhinitis, Veterinary World 7(2): 95-99.

\begin{abstract}
Aim: Isolation and identification of Paturella multocida from pigs of Mizoram with or without clinical lesions of progressive atrophic rhinitis (PAR) followed by their detection, capsular typing and screening for toxA gene.

Materials and Methods: Four hundred nasal swabs sampled from pigs were collected from 6 different districts of Mizoram. Swabs were processed for detection and isolataion of $P$. multocida by PCR and traditional bacteriological assays. Isolates were subjected for multiplex PCR for capsular typing, detection of toxA gene and characterization by RAPD-PCR. Isolates were also tested for antimicrobial sensitivity profile by disc-diffusion method.

Results: A total of 21 swabs were found to be positive by P. multocida species specific PCR (PM-PCR) with an amplicon of $460 \mathrm{bp}$, of which P. multocida could be isolated from 15 swabs (3.75\%). All the isolates were grouped under capsular type A $(\mathrm{n}=9)$ and $\mathrm{D}(\mathrm{n}=6)$ by multiplex PCR. All the isolates were found to be negative for toxA gene by PCR, indicating the isolates as non-toxigenic. Isolates under similar capsular type provided a unique banding pattern by RAPD-PCR, whereas no discrimination was observed between serotypes.
\end{abstract}

Conclusion: Although, no isolates exhibited toxA gene by PCR, isolataion of P. multocida of capsular type A and D may be an indication of their possible role in PAR in pigs of Mizoram.

Keywords: Mizoram, PAR, Pasteurella multocida

\section{I ntroduction}

Progressive atrophic rhinitis (PAR) is a widely prevalent, upper respiratory tract disease of swine characterized by sneezing, snuffling, nasal discharge, epistaxis, growth retardation, reduction in feed utilization, degeneration and atrophy of the nasal turbinate bone leading to visible distortion and shortening of the snout [1]. Moreover, it has been recognized as a contributor to debilitating and fatal porcine pneumonia for at least 120 years and continues to be sustained, unabated with high prevalence in different part of the world [2]. Toxigenic strains of $P$. multocida (both capsular type A and D) alone, or combined with environmental factors like dust, ammonia and other physical or chemical irritants are the primary causes of atrophic rhinitis [3].

Livestock plays an important role in this hilly state of Mizoram, as crop production is still traditional. Amongst the livestock, pig is most important and almost every family rears pig as backyard venture. Since the pig rearing is an important sector in rural economy in this region, a better understanding of PAR and its impact on animal husbandry and economy is essential. Studies on PAR should provide a foundation

Copyright: The authors. This article is an open access article licensed under the terms of the Creative Commons Attribution License (http://creativecommons.org/licenses/by/2.0) which permits unrestricted use, distribution and reproduction in any medium, provided the work is properly cited. for induction of the experimental disease, development of improved diagnostics, development of effective therapeutic/ prophylactic pharmaceutical approaches and development of immunoprophylactic products for effective control of the disease.

There is paucity of information regarding PAR in pigs in India, particularly in North Eastern Region. Therefore, the present study was conducted for isolation and identification of $P$. multocida from nasal cavities of pigs of Mizoram with or without clinical lesions of PAR followed by their detection, capsular typing and screening for toxA gene by PCR based assays.

\section{Materials and Methods}

Sampling: 400 nasal swabs were collected from pigs of different age groups of either sex from 6 districts of Mizoram during June 2010 to May 2011. Of the 400 pigs, 9 were showing respiratory distress as a suspected case of atrophic rhinitis. Samples were collected from local household pigs as well as from organized pig farms.

Detection of P. multocida by PCR assay: Each swab was grown in Brain-Heart Infusion (BHI) broth overnight at $37^{\circ} \mathrm{C}$. After incubation, $1 \mathrm{ml}$ of bacterial suspension was centrifuged at $7084 \mathrm{~g}$. The bacterial pellet was washed thrice with sterile normal saline solution (NSS) $(0.85 \% \mathrm{w} / \mathrm{v})$ and resuspended in $300 \mu \mathrm{l}$ 
Table-1. Oligonucleotide primers used in the present study

\begin{tabular}{|c|c|c|c|c|}
\hline Sr. No. & Name of Primers & Sequence (5'-3') & Expected amplicon size (bp) & Reference \\
\hline 1 & KMT1T7-F & ATCCGCTATTTACCCAGTGG & 460 & 17 \\
\hline 2 & KMT1SP6-R & GCTGTAAACGAACTCGCCAC & & 17 \\
\hline 3 & CapA-F & TGCCAAAATCGCAGTCAG & 1044 & 17 \\
\hline 4 & CapA-R & TTGCCATCATTGTCAGTG & & 17 \\
\hline 5 & CapB-F & CATTTATCCAAGCTCCACC & 760 & 17 \\
\hline 6 & CapB-R & GCCCGAGAGTTTCAATCC & & 17 \\
\hline 7 & CapD-F & TTACAAAAGAAAGACTAGGAGCCC & 657 & 17 \\
\hline 8 & CapD-R & САTCTACССАСТСAАСCATATCAG & & 17 \\
\hline 9 & CapF-F & AATCGGAGAACGCAGAAATCAG & 851 & 17 \\
\hline 10 & CapF-R & TTCCGCCGTCAATTACTCTG & & 9 \\
\hline 11 & to $x A-F$ & TACTCAATTAGAAAAAGCGCTTTATCTTCC & 1230 & 9 \\
\hline 12 & toxA-R1 & TCCCAGTAATTTGTCTGTATTTTATCAAAT & & 9 \\
\hline 13 & toxA-R2 & TCTACTACAGTTGCTGGTATTTTTAAAATAT & & 10 \\
\hline 14 & RAPD-PCR & GTGGTGGTGGTGGTG & & \\
\hline
\end{tabular}

Table-2. PCR based screening and isolation of Pasteurella multocida from nasal swabs collected from 6 different districts of Mizoram.

\begin{tabular}{llcccc}
\hline SI. No. & Place of collection & Samples collected & PM- PCRScreening Results & P. multocida isolated & Capsular types \\
\hline 1 & Aizawl & 185 & 9 & 6 & $\mathrm{~A}(1) ; \mathrm{D}(5)$ \\
2 & Lunglei & 97 & 3 & 3 & $\mathrm{~A}(2) ; \mathrm{D}(1)$ \\
3 & Kolasib & 40 & 2 & 2 & $\mathrm{~A}(2)$ \\
4 & Serchhip & 40 & 2 & 2 & $\mathrm{~A}(2)$ \\
5 & Champhai & 38 & 5 & 2 & $\mathrm{~A}(2)$ \\
& Total & 400 & 21 & 15 & \\
\hline
\end{tabular}

of sterile nuclease free water and boiled in a water bath for 10 minutes followed by immediate chilling. The supernatant was used as template DNA for PCR. PMPCR assay was conducted for the detection of $P$. multocida as described earlier [4].

Mouse inoculation: Each PM-PCR positive culture was injected intraperitoneally to Swiss albino mice $(0.2$ $\mathrm{ml} /$ mice) and observed for $72 \mathrm{hrs}$. The heart blood and spleen were collected aseptically during postmortem examination and were inoculated on 5\% sheep blood agar plate. Plates were incubated at $37^{\circ} \mathrm{C}$ for overnight. $P$. multocida were isolated and identified using standard bacteriological methods.

Capsular typing of P. multocida isolates by multiplex PCR assay: All the isolates were subjected to multiplex PCR assay to determine their capsular group. Each PCR reaction mixture $(25 \mu \mathrm{l})$ containing the following: each primer (capsular group A, B, D, E and F; Table-1) with concentrations of $3.2 \mu \mathrm{M}, 200 \mu \mathrm{M}$ of each dNTPs, 1x PCR buffer, $1.5 \mathrm{mM} \mathrm{MgCl}_{2}, 1 \mathrm{U}$ of Taq DNA polymerase and $4 \mu \mathrm{l}$ of template DNA. The following standard cycling procedure was used for DNA amplification: initial denaturation at $95^{\circ} \mathrm{C}$ for $5 \mathrm{~min}$, followed by 30 cycles of denaturation at $95^{\circ} \mathrm{C}$ for $30 \mathrm{sec}$, annealing at $55^{\circ} \mathrm{C}$ for $30 \mathrm{sec}$, extension at $72^{\circ} \mathrm{C}$ for $30 \mathrm{sec}$ and a final extension at $72^{\circ} \mathrm{C}$ for $6 \mathrm{~min}$. The standard reference strain of $P$. multocida serotype B:2 was included as a positive control and the negative control had no template DNA.

Detection of toxA gene by toxA gene specific PCR assay: toxA gene specific PCR was performed [5] by a colony touch PCR mixture $(25 \mu \mathrm{l})$ containing $3.2 \mu \mathrm{M}$ of each primer, $200 \mu \mathrm{M}$ of each dNTPs, 1x PCR buffer, $1.5 \mathrm{mM} \mathrm{MgCl}$ and $1 \mathrm{U}$ of Taq DNA polymerase. The following standard cycling procedure was used for DNA amplification: initial denaturation at $95^{\circ} \mathrm{C}$ for 5 min, followed by 30 cycles of denaturation at $95^{\circ} \mathrm{C}$ for $30 \mathrm{sec}$, annealing at $55^{\circ} \mathrm{C}$ for $30 \mathrm{sec}$, extension at $72^{\circ} \mathrm{C}$ for $30 \mathrm{sec}$ and a final extension at $72^{\circ} \mathrm{C}$ for $6 \mathrm{~min}$.

Randomly amplified polymorphic DNA-PCR: RAPDPCR [6] reaction mixture $(25 \mu \mathrm{l})$ was prepared using $1 \mathrm{X}$ Dream Taq buffer (with $30 \mathrm{mM} \mathrm{MgCl}$ ), dNTPs $(0.2$ mM each), RAPD primer $(3.5 \mu \mathrm{M}), 2.0 \mathrm{U}$ of Taq DNA polymerase and $4.0 \mu \mathrm{l}$ of template DNA. The reaction mixture was subjected to DNA amplification by following cycling conditions: initial denaturation at $94^{\circ} \mathrm{C}$ for $5 \mathrm{~min}$, followed by 35 cycles of denaturation at $94^{\circ} \mathrm{C}$ for $1 \mathrm{~min}$, annealing at $38^{\circ} \mathrm{C}$ for $1 \mathrm{~min}$ and extension at $72^{\circ} \mathrm{C}$ for $1 \mathrm{~min}$. It was followed by a final extension at $72^{\circ} \mathrm{C}$ for $6 \mathrm{~min}$.

Amplified products were separated by agarose gel electrophoresis ( $2 \%$ agarose in $0.5 \mathrm{x}$ Tris-borate-EDTA buffer) at $5 \mathrm{~V} / \mathrm{cm}$ for $2 \mathrm{~h}$ and stained with ethidium bromide $(0.5 \mu \mathrm{g} / \mathrm{ml})$. A standard molecular marker (100 bp DNA ladder) was included in each gel. DNA fragments were observed by ultraviolet transilluminator and photographed by gel documentation system (Alpha Imager, Germany).

Antimicrobial drugs sensitivity assay of P. multocida: All the isolates were subjected to in vitro antibiotic sensitivity test by disc diffusion method [7] using 14 commercially available antimicrobial agents.

\section{Results}

PCR based screening of nasal swabs: Of the 400 nasal swabs, 21 animals including the 9 PAR suspected animals, were found to be positive by PM-PCR for a product of $460 \mathrm{bp}$, which is specific for $P$. multocida. Of the 21 positive samples, 9, 3, 2, 2 and 5 were sampled from Aizawl, Lunglei, Kolasib, Serchhip and Champhai district, respectively (Table-2 and Fig-1).

I solation and identification of P. multocida: A total of 


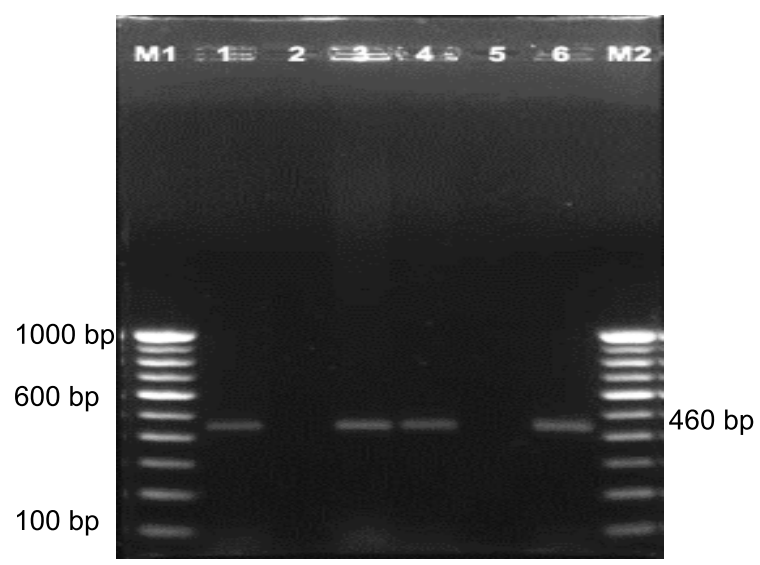

Figure-1. Detection of Pasteurella multocida by species specific PCR

Lane M1 and M2: 100 bp DNA ladder, Lane 1: Positive control, Lane 2: Negative control, Lane 3: Sample no. Pm 5, Lane 4: Sample no. Pm 10, Lane 5: Negative sample and Lane 6: Sample no. Pm 15.

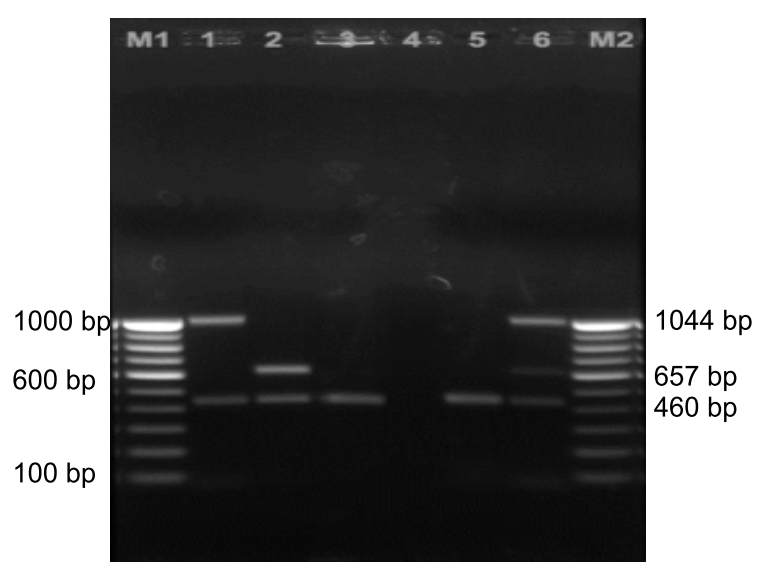

Figure-2. Capsular typing of Pasteurella multocida by multiplex PCR

Lane M1 and M2: 100 bp DNA ladder, Lane 1: Capsular type A, Lane 2: Capsular type D, Lane 3: P. multocida, Lane 4: Negative control, Lane 5: P. multocida and Lane 6: Positive control for capsular type A and D.

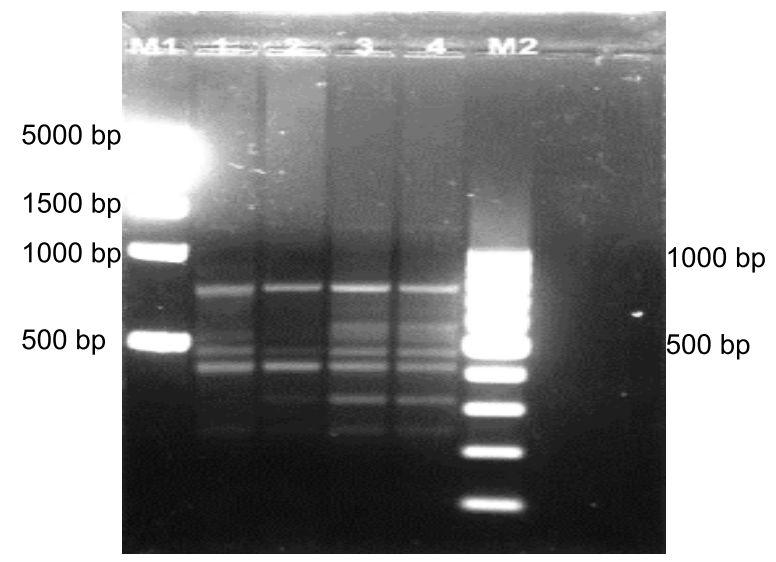

Figure-3. RAPD-PCR analysis of Pasteurella multocida isolates.

Lane M1: 500 bp DNA ladder, Lane M2: 100 bp DNA ladder, Lane 1 and 2: Representative P. multocida isolates of Capsular type D, Lane 3 and 4: Representative P. multocida isolates of Capsular type $A$.

$15 P$. multocida were isolated and identified and designated as Pm1 to Pm15 (Table-1). P. multocida was isolated from all the 9 clinically suspected PAR pigs. Out of 391 apparently healthy pigs, $P$. multocida was isolated from only 6 pigs.

Capsular typing of P. multocida by multiplex PCR assay: Of the $15 \mathrm{P}$. multocida isolates $9(60 \%)$ and 6 (40\%) were identified as capsular type A (1044 bp) and capsular type D (657 bp), respectively (Table-1, Fig-2). Of the 9 isolates from PAR suspected positive animals, 3 and 6 isolates were identified as capsular type $A$ and $\mathrm{D}$, respectively. On the other hand, all the 6 isolates from apparently healthy animals contained capsular type A only.

Detection of toxA gene by toxA gene specific PCR assay: All the 15 isolates tested for the toxA gene were found to be negative for an expected amplicon of 1230 bp.

Randomly amplified polymorphic DNA - PCR (RAPDPCR): RAPD-PCR of all the 15 P. multocida isolates provided a range of amplicons between 400-1400 bp with a high degree of discrimination between capsular type A and D. All 9 isolates of capsular type A showed similar banding pattern, and similarly, all 6 isolates of capsular type D exhibited same banding pattern (Fig - 3).

Antimicrobial sensitivity test: PAR in pigs can be treated with potentiated sulphonamides, ampicillin, tetracyclines, ceftiofur or enrofloxacin. Support therapy such as additional food and electrolytes may be necessary. In the present study, majority of the isolates exhibited $100 \%$ sensitivity against amoxicillin, cephalexin, chloramphenicol, ciprofloxacin, cotrimoxazole, enrofloxacin, erythromycin, gentamicin, ofloxacin, rifampicin and tetracycline. However, three antibiotics did not show $100 \%$ sensitivity. The order of sensitivity were oxytetracycline $(93 \%)$ followed by ampicillin (87\%) and amikacin (47\%) (Table-3).

\section{Discussion}

The PM-PCR assay used in this study was highly specific and sensitive and direct use of the confluent growth culture provided rapid detection of $P$. 
Table-3. Antimicrobial drug sensitivity assay of $15 \mathrm{P}$. multocida isolates

\begin{tabular}{llcc}
\hline Sr. No. & Antimicrobial agents & Concentration per disc & Sensitive( $\mathbf{n = 1 5 )}$ \\
\hline 1 & Amikacin (AK) & $30 \mathrm{mcg}$ & $7(47 \%)$ \\
2 & Amoxycillin (AM) & $30 \mathrm{mcg}$ & $15(100 \%)$ \\
3 & Ampicillin (A) & $10 \mathrm{mcg}$ & $13(87 \%)$ \\
4 & Cephalexin (CP) & $30 \mathrm{mcg}$ & $15(100 \%)$ \\
5 & Chloramphenicol (C) & $30 \mathrm{mcg}$ & $15(100 \%)$ \\
6 & Ciprofloxacin (CF) & $5 \mathrm{mcg}$ & $15(100 \%)$ \\
7 & Co-trimoxazole (CO) & $25 \mathrm{mcg}$ & $15(100 \%)$ \\
8 & Enrofloxacin (EX) & $10 \mathrm{mcg}$ & $15(100 \%)$ \\
9 & Erythromycin (E) & $15 \mathrm{mcg}$ & $15(100 \%)$ \\
10 & Gentamicin (G) & $10 \mathrm{mcg}$ & $15(100 \%)$ \\
11 & Ofloxacin (OF) & $5 \mathrm{mcg}$ & $15(100 \%)$ \\
12 & Oxytetracycline (O) & $30 \mathrm{mcg}$ & $14(93 \%)$ \\
13 & Rifampicin (R) & $5 \mathrm{mcg}$ & - \\
14 & Tetracycline (T) & $30 \mathrm{mcg}$ & - \\
& & & - \\
\end{tabular}

multocida, regardless of the purity of the samples. Similar method of bacterial isolation was also followed by other research groups in India and abroad $[8,9]$. In routine diagnostic procedure, it is difficult to obtain a pure culture of $P$. multocida from clinical samples because of contaminants and/or death of organisms. Therefore, only PM-PCR positive samples could yield isolation of the organism.

All the $21 \mathrm{PM}-\mathrm{PCR}$ positive cultures in BHI broth were inoculated in mice individually for isolation of $P$. multocida. The organism was isolated from heart blood and spleen of dead mice. When the same samples were inoculated directly on 5\% sheep blood agar, isolation rate of $P$. multocida was poor $(70 \%)$. Similar observations were also recorded by other workers with a success rate of approximately $18.0 \%$, because of frequent overgrowth of contaminants [10]. Use of PMPCR and subsequent mice inoculation for screening of nasal swabs drastically reduced the time for isolation of P. multocida.

The present study recorded relatively low recovery of $P$. multocida from nasal swabs collected from Mizoram. This might be due to the random sampling of the animals. Although the sample size might be low for any conclusive remarks, it revalidates the fact that $P$. multocida is a common inhabitant of pig in the nasopharyngeal area. Isolation of P. multocida from aperantly healthy pigs indicated that these animals were prone to disease under stress conditions. Kalorey et al. [11] have also recorded an outbreak of pasteurellosis with high mortality in indigenous pigs in India.

The PCR based capsular typing assay [11] was found to be a rapid and extremely reliable assay for determining the capsular types of a large number of $P$. multocida isolates. In the present study, $9(60 \%)$ and 6 $(40 \%)$ isolates were capsular type A and D, respectively. None of the isolates were untypeable. Capsular type $\mathrm{F}$ and untypeable are uncommon in pigs but are often isolated from avian species. However, Choi et al. [12] identified 21 untypeable strains among $203 P$. multocida isolates from pneumonic pigs in Korea. The present study showed higher percentage of capsular type A (60\%), compared to capsular type D (40\%), which is in agreement with previous studies $[12,13]$.
Toxigenic P. multocida is recognized as a causative agent of PAR in pigs. It has been isolated with almost equal frequency from pigs with or without the signs of PAR. However, the herds with clinical PAR had a higher prevalence of capsular type $\mathrm{D}$ toxigenic $P$. multocida and a lower prevalence of capsular type A non-toxigenic $P$. multocida [8,14]. Moreover, pigs with signs of respiratory tract infection mainly developed the symptoms similar to pneumonia. The result of this study is also in accordance with the previously published reports by various research groups [9]. Ranjan et al. [15] also described that toxA gene based PCR can be used for direct analysis of toxigenic $P$. multocida without additional hybridization. This assay appears to be the most sensitive and effective method for large scale analysis of nasal and tonsillar swabs.

RAPD-PCR showed that capsular type A and D $P$. multocida isolates exhibited two different banding patterns ranging between $400-1400 \mathrm{bp}$ (Fig - 3). The correlation between RAPD pattern and capsular type helped in differentiating the isolates belonging to the same species. In the present study, it was also observed that RAPD pattern of $P$. multocida capsular type A was different from that of capsular type $\mathrm{D}$, but no discriminatory patterns were recorded within the same capsular type (Fig.-3). Dutta et al. [6] observed the polymorphism in 33 isolates of $P$. multocida, isolated from rabbits and reported it as an efficient and reproducible technique. Dutta et al. [6,16] characterized $P$. multocida strains of different serotypes by RAPD and observed a unique banding pattern for individual serotypes.

Majority of the isolates were sensitive to amoxicillin, cephalexin, chloramphenicol, ciprofloxacin, cotrimoxazole, enrofloxacin, erythromycin, gentamicin, ofloxacin, rifampicin and tetracycline (100\%) followed by oxytetracycline (93\%), ampicillin (87\%) and amikacin (47\%). The lower sensitivity of amikacin could be due to the gradual development of resistance towards these antimicrobial drugs. Higher efficacy of enrofloxacin and ofloxacin along with chloramphenicol has also been reported by Sharma et al. [17] in an in vitro study. Enrofloxacin and chloram-phenicol were found to be quite effective against pasteurellosis by several research groups [18]. 


\section{Conclusion}

Although, no isolates exhibited toxA gene by PCR, isolataion of $P$. multocida of capsular type A and $\mathrm{D}$ may be an indication of their possible role in PAR in pigs of Mizoram. In the last two decades, shift in antibiotic sensitivity spectrum of pasteurella is well evident from observed clinical resistance against conventional antibiotics, which lead to problems in treating the animals suffering from pasteurellosis. This warrants the need for pre-testing of antibiotics sensitivity against pasteurella, so as to find out an effective antimicrobial agent to be used by the veterinarian.

\section{Authors' contributions}

ZV: Collection of Samples, processing for isolation and identification of $P$. multocida. TKD: Planning of research methodology, technical support, manuscript preparation. PR: Processing of samples for PCR and analysis. JB: Antibiotic sensitivity assay of the isolates. $\mathrm{RC}$ : Overall supervision of the work, editing of the manuscript. All authors read and approved the final manuscript.

\section{Acknowledgements}

The authors are highly thankful to the "Institutional Biotech Hub", College of Veterinary Science and Animal Husbandry (CVSc\&AH), Central Agricultural University (CAU), Aizawl which is funded by Department of Biotechnology, Government of India for providing the required instrumentation facilities. The atuhors are also thankful to the Dean, CVSc\&AH, CAU, Aizawl, Mizoram for providing infrastructure facilities to conduct the research work.

\section{Competing interests}

The authors declare that they have no competing interests.

\section{References}

1. Rushton, J. (2009) Diseases of pigs. In : The economica of animal health and production. CAB International, Oxfordshire, UK. Pp : 248-255.

2. OIE Terrestrial Manual (2012) Atrophic Rhinitis of Swine. Chapter 2.8.2.

3. Hamilton, T.D., Roe, J.M. and Webster, A.J.E. (1996) Synergistic role of gaseous ammonia in etiology of Pasteurella multocida as well as bacteria free crude extracts and purified dermonecrotic toxin of Pasteurella multocida. Am. J. Vet. Res. 49: 1844-1849.

4. Markam, S.K., Khokhar, R.S., Kapoor, S. and Kadian, S.K. (2009) Molecular characterization of field isolates of Pasteurella multocida by polymerase chain reaction in the state of Haryana. Indian J. Comp. Microbiol. Immunol. Infect. Dis., 30 (1): 31-34.

5. Babita Devi L (2012) Molecular characterization of Pasteurella multocida of porcine origin. Ph.D. theis. Submitted to Assam Agricultural University, Jorhat, Assam.

6. Dutta, T.K., Singh, V.P. and Kumar, A.A. (2009) Molecular detection and characterization of Indian isolates of Pasteurella multocida serogroup D. Indian. J. Anim. Sci. 79: 11-14.

7. CLSI. (2011) Performance standards for antimicrobial susceptibility testing, 21st international supplement. CLSI M100-S21. Clinical and Laboratory Standards Institute, Wayne, PA.

8. Biswas, A., Shivachandra, S.B., Saxena, M.K., Kumar, A.A., Singh, V.P. and Srivastava, S.K., (2004) Molecular variability among strains of Pasteurella multocida isolated from an outbreak of haemorrhagic septicemia in India. Vet. Res. Comm., 28: 287-298.

9. Kalorey, D.R., Yusuraj, S., Vanjari, S.S., Gunjal, P.S., Dhanawade, N.B., Barbuddhe, S.B. and Bhandarkar, A.G. (2008) PCR analysis of Pasteurella multocida isolates from an outbreak of pasteurellosis in Indian pigs. Comp. Immunol. Microbiol. Infect. Dis., 31: 495-465.

10. Amigot, J.A., Torremorell, M. and Pijoan, C. (1998) Evaluation of techniques for the detection of toxigenic Pasteurella multocida strains from pigs. J. Vet. Diagn. Invest., 10: 169-173.

11. Townsend, K.M., Boyce, J.D., Chung, J.Y., Frost, A.J. and Adler, B. (2001) Genetic organization of Pasteurella multocida cap Loci and development of a multiplex capsular PCR typing system. J. Clin. Microbiol., 39: 924-929.

12. Choi, C., Kim, B., Cho, W.S., Kim, J., Kwon, D., Cheon, D.S. and Chae, C. (2001) Capsular serotype, toxA gene and antimicrobial susceptibility profiles of Pasteurella multocida isolated from pigs with pneumonia in Korea. Vet. Rec., 149: 210-212.

13. Zhao, G., Pijoan, C., Murtaugh, M.P. and Molitor, T.W. (1992) Use of restriction endonuclease analysis and ribotyping to study epidemiology of Pasteurella multocida in closed swine herds. Infect. Immunol, 60: 1401-1405.

14. Gardner, I.A., Kasten, R., Eamens, G.J., Snipes, K.P. and Anderson, R.J. (1994) Molecular fingerprinting of Pasteurella multocida associated with progressive atrophic rhinitis in swine herds. J. Vet. Diagn. Invest., 6: 442-447.

15. Ranjan, R., Panda, S.K., Acharya, A.P., Singh, A.P. and Gupta, M.K. (2011) Molecular diagnosis of Haemorrhagic Septicaemia- A review. Vet. World, 4: 189-192.

16. Dutta, T.K., Gautam, R., Singh, V.P. and Kumar, A.A. (2004) Molecular detection and characterization of Indian isolates of Pasteurella multocida serogroup 'A'. Indian. J. Anim. Sci., 74: 244-247.

17. Sharma, S.P., Sharma, R.K. and Aahman, H. (2005) Isolation, serotyping and antibiogram of Pasteurella from pigs of North-East India. Indian. J. Anim. Sci., 74: 905-907.

18. Portis, E., Lindeman, C., Johansen, L. and Stoltman, G. (2012) A ten-year (2000-2009) study of antimicrobial susceptibility of bacteria that cause bovine respiratory disease complex--Mannheimia haemolytica, Pasteurella multocida, and Histophilus somni--in the United States and Canada. J Vet Diagn Invest. 24(5):932-44. 